\title{
Between Curing and Torturing: Burden of Adverse Reaction in Drug-Resistant Tuberculosis Therapy
}

\author{
Yudisia Ausi iD 1,2 \\ Prayudi Santoso id ${ }^{3}$ \\ Deni Kurniadi Sunjaya (D) 4 \\ Melisa Intan Barliana (D) ${ }^{1,5}$ \\ 'Department of Biological Pharmacy, \\ Faculty of Pharmacy, Universitas \\ Padjadjaran, Bandung, Indonesia; ${ }^{2}$ Master \\ Program in Clinical Pharmacy, Faculty of \\ Pharmacy, Universitas Padjadjaran, \\ Bandung, Indonesia; ${ }^{3}$ Department of \\ Internal Medicine, Faculty of Medicine, \\ Universitas Padjadjaran, Bandung, \\ Indonesia; ${ }^{4}$ Department of Public Health, \\ Faculty of Medicine, Universitas \\ Padjadjaran, Bandung, Indonesia; ${ }^{5}$ Center \\ of Excellence in Higher Education for \\ Pharmaceutical Care Innovation, \\ Universitas Padjadjaran, Bandung, \\ Indonesia
}

\begin{abstract}
Drug-resistant tuberculosis (DR-TB) requires prolonged and complex therapy which is associated with several adverse drug reactions (ADR). The burden of ADR can affect the quality of life (QoL) of patients that consists of physical, mental, and social wellbeing, and influences the beliefs and behaviors of patient related to treatment. This article reviews the burden of ADR and its association with QoL and adherence. We used PubMed to retrieve the relevant original research articles written in English from 2011 to 2021. We combined the following keywords: "tuberculosis," "Drug-resistant tuberculosis," "Side Effect," "Adverse Drug Reactions," “Adverse Event," "Quality of Life," “Adherence," "Non-adherence," "Default," and "Loss to follow-up." Article selection process was unsystematic. We included 12 relevant main articles and summarized into two main topics, namely, 1) ADR and QoL (3 articles), and 2) ADR and therapy adherence ( 9 articles). The result showed that patients with ADR tend to have low QoL, even in the end of treatment. Although it was torturing, the presence of ADR does not always result in non-adherence. It is probably because the perception about the benefit of the treatment dominates the perceived barrier. In conclusion, burden of ADR generally tends to degrade QoL of patients and potentially influence the adherence. A comprehensive support from family, community, and healthcare provider is required to help patients in coping with the burden of ADR. Nevertheless, the regimen safety and efficacy improvement are highly needed.
\end{abstract}

Keywords: drug-resistant tuberculosis, adverse drug reaction, quality of life, adherence

\section{Introduction}

Drug-resistant tuberculosis (DR-TB) remains a global public health problem. It is defined as a disease caused by Mycobacterium tuberculosis bacteria that have been resistant to the standard antimicrobial treatment. In 2019, approximately 465,000 people with TB were resistant to rifampicin or called rifampicin-resistant TB (RR TB), of which 78\% were multidrug-resistant TB (MDR-TB). MDR is a condition when bacteria are resistant to both Isoniazid and Rifampicin as the two most potent antituberculosis drugs. Unlike drug-susceptible tuberculosis (DS-TB) treatment, which only requires first line antituberculosis, $\mathrm{RR} / \mathrm{MDR}-\mathrm{TB}$ treatment requires a combination of second line antituberculosis drugs. Recent WHO recommendation of RR/MDR-TB treatment has categorized antituberculosis agent into 3 groups. Group A consists of bedaquiline, fluoroquinolone (levofloxacin/moxifloxacin), and linezolid. Group $\mathrm{B}$ consists of clofazimine and cycloserine/terizidone. Group $\mathrm{C}$ consists of ethambutol, delamanid, pyrazinamide, imipenem-cilastatin/meropenem, amikacin, streptomycin, ethionamide/prothionamide, p-aminosalicylic acid. Combination of all drugs from group A and at least one drug from group B is recommended as a standard treatment
Correspondence: Melisa Intan Barliana Department of Biological Pharmacy, Faculty of Pharmacy, Universitas Padjadjaran, Jl. Raya Bandung Sumedang KM. 2I, Jatinangor, Bandung, Indonesia, 45363

Email melisa.barliana@unpad.ac.id 
of long-term regimen, while group $\mathrm{C}$ can be administered when main drugs from group $A$ and $B$ cannot be used. Longterm regimen requires $18-24$ months of therapy, this is 3-4 times longer than DS-TB therapy which only requires 6 months of therapy. Yet, for patients with certain conditions, the duration can be shortened to 9-12 months or called shortterm regimen. ${ }^{1,2}$

DR-TB therapy is quite challenging owing to prolonged duration, more complex, and more toxic regimens that likely cause adverse drug reactions (ADR). ${ }^{1,2}$ ADR is a response to a drug that is noxious, unintended, and occurs at doses normally used in man for prophylaxis, diagnosis, or therapy of disease, or for the modification of a physiological function. ${ }^{3}$ The severity of ADR can be categorized in major (consists of fatal, life-threatening, severe) and minor (consists of mild, moderate) types. ${ }^{4}$ Several ADR of DR-TB therapy regimens that have been reported included gastrointestinal (GI) disturbances as the most common ADR (induced by p-aminosalicylic acid, pyrazinamide, ethambutol, and ethionamide), ototoxicity (aminoglycoside), peripheral neuropathy (isoniazid, cycloserine, ethambutol, ethionamide), psychiatric disorders (cycloserine, fluoroquinolone), QT prolongation (delamanid, bedaquiline, fluoroquinolone), hypothyroidism (p-aminosalicylic acid, ethionamide), dermatologic disorders (pyrazinamide, clofazimine), renal impairment (aminoglycoside), vision problems (ethambutol, linezolid), electrolyte imbalance (aminoglycoside), hepatic dysfunction (all), seizures (cycloserine, isoniazid, fluoroquinolone), Arthralgia (fluoroquinolone, pyrazinamide), dizziness, and headaches. ${ }^{5-12}$ Some ADR even persist after the therapy ended. ${ }^{4,5,13}$

ADR are burdensome and interfere with daily life activities and the well-being of patients. ${ }^{14,15}$ The burden can inflict poor quality of life (QoL), as patients had to spend a lot of energy, time, and resources to deal with their conditions that potentially influenced their beliefs and behaviors related to their treatments. ${ }^{15,16}$ Finally, it results in increasing the risk of non-adherence that led to unachieved therapy goals and poor treatment outcomes. ${ }^{15}$

Although many studies about ADR have been published, only a few discussed the impact on the well-being or QoL of patients quantitatively, while many of them focused on the prevalence and ADR types. Given that the QoL is important, it may impact adherence as a critical concern of DR-TB therapy, and both topics should be understood properly. Therefore, the literature review was written to discuss the 1) association between
ADR and health-related QoL, and 2) association between ADR and therapy adherence. A comprehensive discussion about ADR, QoL, and adherence in DR-TB patients helps to demonstrate burden of ADR from psychosocial perspective. This review is expected to be the source of information for healthcare providers in understanding the burden of ADR that frequently occur in DR-TB patients.

\section{Materials and Methods}

We searched for articles in PubMed with the use of the following keyword combinations to meet the aim of this study: "tuberculosis," "Drug-resistant tuberculosis," "Side Effect," "Adverse Drug Reactions," "Adverse Event," "Quality of Life," “Adherence," "Non-adherence," "Default," and "Loss to follow-up." We included original research studies written in English from 2011 to 2021. The identification of articles and the selection process were not systematic. The flow of article selection is illustrated in Figures 1 and 2. Only original research studies with quantitative methods were selected as the main articles. Articles on unrelated topics were excluded. The results were summarized into two main topics, namely, 1) ADR and Health Related-QoL, and 2) ADR and therapy adherence. The search strategy identified 12 quantitative research papers as the main articles.

\section{ADR and Health-Related QoL}

QoL is a multidimensional concept that represents the perceived position of an individual regarding physical health, psychological condition, social relationships, personal beliefs, level of independence, and his/her relationship to environment. ${ }^{17}$ When it corresponds to or affected by the presence of disease or treatment, it is called healthrelated QoL (HR QoL). ${ }^{18} \mathrm{HR}$ QoL is one healthcare system output that is important to be measured. It is broader than biological functioning and morbidity. ${ }^{19}$

Some research had proven that tuberculosis and its consequences affected HR-QoL not only due to somatic symptom but also had psychological and social impacts. ${ }^{20-22}$ Moreover, in DR-TB, long-term therapy and toxic drugs render the implementation of curing processes more difficult. $^{23}$ A systematic review has reported that the HRQoL of MDR-TB patients was considerably lower than DSTB patients, especially in the first six months of therapy. ${ }^{24,25}$ ADR is one of the predictors of HR-QoL in DR-TB patients in addition to other sociodemographic factors, such as age, family support, sex, education, marital status, and clinically related factors, such as TB history, 


\section{8 potentially relevant articles were identified through PubMed search}

\section{5 potentially relevant articles were identified through PubMed search}

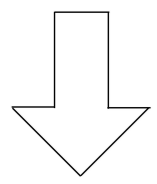

\section{6 articles were excluded:}

Full-text unavailable (22)

Not original research paper (54)

Not related to ADR and therapy adherence of DR TB patients (440)

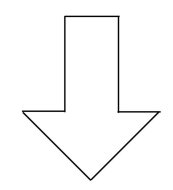

\section{3 articles were included}

Figure I Flowchart of article selection process for Topic I (ADR and HealthRelated QoL).

baseline lung cavity, sickness before diagnosis, positive diagnosis of human immunodeficiency virus (HIV), and usage of injectable drugs. ${ }^{22,25-29}$

The research on this topic remains scarce. Three studies investigated associations of ADR with the patients' HRQoL in DR-TB patients (Table 1). One of these investigated both DS-TB and DR-TB. Two of the studies indicated associations between ADR and HR-QoL. ${ }^{20,22}$ A study reported by Sineke used the SF-36 questionnaire to investigate the mental component summary (MCS) and the physical component summary (PCS). DR-TB patients with reported ADR more likely had lower MCS (aRR 2.24 95\% confidence interval (CI) 1.53-3.27) and PCS (aRR $1.5295 \%$ CI 1.07-2.18) scores than patients who did not report ADR. The mental score was found to be lower than

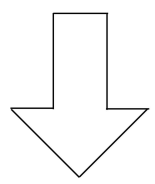

\section{9 articles were included}

Figure 2 Flowchart of article selection process for Topic 2 (ADR and Therapeutics Adherence).

physical score. This means that physical health recovers faster than mental health. ${ }^{22}$

ADR during the early month of therapy has reduced HR-QoL substantially. Usage of injectable drugs also contributed to the deterioration of HR-QoL. Patients with injectable drugs were 1.49 times more likely to have low MCS scores than patients with injection-free regimens. ${ }^{22}$

A study conducted by Valadares et al investigated the association between ADR and QoL in a TB population consisted of DS-TB and DR-TB. Patients who suffered both minor and major ADR had worse QoL than patients with minor ADR only. ${ }^{20}$

Contradictory results were reported by Sagwa et al that identified no association between QoL and ADR in MDRTB patients. This finding was reasonable because the 
Table I Quantitative Studies of Association Between ADR and QoL in MDR-TB Patients

\begin{tabular}{|c|c|c|c|c|c|}
\hline $\begin{array}{l}\text { Study } \\
\text { Design }\end{array}$ & Setting & Target & $\begin{array}{l}\text { HRQoL } \\
\text { Measurement }\end{array}$ & Summary of Result & Reference \\
\hline $\begin{array}{l}\text { Cross } \\
\text { sectional }\end{array}$ & $\begin{array}{l}\text { Johannesburg, } \\
\text { South Africa, } \\
\text { February 2015- } \\
\text { January } 2018\end{array}$ & $\begin{array}{l}\text { DR-TB Patients; } \geq 18 \text { years old } \\
(n=149)\end{array}$ & Short Form-36 (SF-36) & $\begin{array}{l}\text { Patients with ADR experience were } \\
\text { more likely to have lower MCS (aRR } \\
2.2495 \% \mathrm{Cl} \text { I.53-3.27) and PCS (aRR } \\
\text { I.5295\% Cl I.07-2.I8). }\end{array}$ & $\begin{array}{l}\text { Sineke } \\
\text { et al, } \\
2019^{22}\end{array}$ \\
\hline $\begin{array}{l}\text { Cross } \\
\text { sectional }\end{array}$ & $\begin{array}{l}\text { Namibia, } \\
\text { January-April } \\
2015\end{array}$ & $\begin{array}{l}\text { MDR-TB patients in the final } \\
\text { month or had completed the } \\
\text { treatment within the past } 3 \\
\text { months; aged } 17-54 \text { years ( } n= \\
\text { 36) }\end{array}$ & Short Form-8 (SF-8) & $\begin{array}{l}\text { There was no significant different } \\
\text { between patients reporting zero to } \\
\text { two ADR (median HRQoL score = } \\
56.8 \text {; 44.4-56.8) with those reporting } \\
\text { three or more ADR (median HRQoL } \\
\text { score = } 55.2(38.6-56.8) \text {; ( } \mathrm{p} \text { value = } \\
0.34) \text { ). }\end{array}$ & $\begin{array}{l}\text { Sagwa et al, } \\
2016^{30}\end{array}$ \\
\hline $\begin{array}{l}\text { Cross } \\
\text { sectional }\end{array}$ & $\begin{array}{l}\text { Belo } \\
\text { Horizonte, } \\
\text { Brazil. March- } \\
\text { December } \\
2015 .\end{array}$ & $\begin{array}{l}\text { Both DR-TB and DS-TB } \\
\text { patients, }>18 \text { years old }(n=73)\end{array}$ & $\begin{array}{l}\text { Abbreviated World } \\
\text { Health Organization } \\
\text { Quality of Life } \\
\text { Questionnaire } \\
\text { (WHOQOL-Bref) }\end{array}$ & $\begin{array}{l}\text { There were significant association } \\
\text { between the type of } A D R \text { and } H R Q \circ L \\
\text { in univariate analysis ( } P \text { value }=0.016 \text { ) } \\
\text { and in multivariate analysis ( } p \text { value } \\
=0.012 \text { ). }\end{array}$ & $\begin{array}{l}\text { Valadares } \\
\text { et al, } \\
2020^{20}\end{array}$ \\
\hline
\end{tabular}

Abbreviations: HRQoL, health-related quality of life; ADR, adverse drug reaction; MCS, mental component summary; PCS, physical component summary; aRR, adjusted relative risk; $\mathrm{Cl}$, confidence interval; DR-TB, drug resistant tuberculosis; MDR-TB, multi-drug resistant tuberculosis.

subject underwent the final month of treatment or had completed treatment within the last three months. ${ }^{30}$ Severe side effects frequently suffered in the intensive phase. In the continuation phase there may be several persistent adverse outcomes, such as hearing loss, but it could be tolerated or handled better as therapy progressed, and as the number of medications decreased over time. Therefore, unlike the early phase, the patients in the final month of therapy may have a better QoL. ${ }^{30-32}$ Despite significant HR-QoL improvement in the end of MDR-TB therapy, HR QoL score was considered low which indicated an impairment. ${ }^{26,33}$ Residual impairment of HR-QoL may have happened after prolonged therapy with high pill burden and various ADR. ${ }^{26,34}$ Moreover, the disease itself altered lung architecture and increased risk of Chronic Obstructive Pulmonary Disease (COPD). ${ }^{34}$

\section{Physical Well-Being}

ADR generate physical distress. Major ADR can cause hospitalization, disability, or even death if not managed properly. ${ }^{13}$ A meta-analysis indicates that $57.3 \%$ of MDR-TB patients experienced at least one adverse event. ${ }^{5}$ A higher ADR average was found in a high-prevalence HIV setting (83\%), in which $24 \%$ of the evaluated cases were considered as serious adverse events. GI disturbance such as gastritis, vomiting, and reduced appetite, was the most prevalent $\mathrm{ADR}^{4,6}$ Some patients admitted that they cannot tolerate ADR. Instead of feeling better, patients felt that the outcomes following the intake of medications were as bad as the illness itself, or even worse. ${ }^{35,36}$

Some ADR lead to permanent disability, even when the drug has been discontinued, for example ototoxicity. A study conducted in 50 MDR-TB patients with aminoglycoside injectable agent reported that $28 \%$ of participants experienced ototoxicity and $18 \%$ of participants experienced long-term hearing loss. ${ }^{37}$ Ototoxicity is one of the most common major ADR with a prevalence of $14.6 \%$. Injectable drugs not only cause pain at the injection site but also found to be the most ADR-inducing drugs. ${ }^{37-39}$

\section{Social Well-Being}

Despite the social stigma of the illness itself, ADR also was a burden of social life of patients. Patient missed out a lot of social activities because they felt they are too weak to socialize. For some patients, the visible effects, such as skin discoloration, made them feel ashamed. The ADR prevented them to perform household chores. The inability to work owing to the disease and its adverse effects compelled patients to face income losses. Conversely, they also faced financial constraint to provide adequate nutritious foods and to sustain their treatment. ${ }^{31,39-42}$ Although the treatment itself is free, patients still have to pay some indirect cost, for example transportation cost. ${ }^{43}$ 


\section{Mental Well-Being}

ADR was also associated with psychiatric problems. ${ }^{44}$ A cross-sectional study showed that $33.8 \%$ patients were depressed. Qualitative data indicated that the majority of patients feel depressed owing to side effects. ${ }^{45}$ Another study revealed that the side effects were the most significant factors of depression among MDR-TB patients (aOR 20.7, 95\% CI 1.2-355.7). ${ }^{44}$ Patients were often depressed. ${ }^{45}$ Some patients felt that their lives were only about disease and treatment. ${ }^{40}$ Patients were very tortured and even some of them said that they would rather die than experience this type of terrible feeling. ${ }^{46}$ The worthless feeling and disability also made them feel depressed. ${ }^{45}$ Furthermore, psychiatric disorders were included in the major ADR of some drugs. A prior study reported that it occurred in $13.2 \%$ of patients. ${ }^{5}$ The manifestations of these disorders can be anxiety, depression, and psychosis that may sometimes lead to suicidal attempts. ${ }^{5,6,47}$ It could be induced by cycloserine and fluoroquinolone. ${ }^{48}$ Depression and other mental problems as a consequence of DR-TB therapy may exacerbate non-adherences. ${ }^{45}$

\section{ADR and Therapeutics Adherence}

ADR constitute one of the challenging aspects that may exacerbate the burden of illness. Burdened patients sometimes struggle with adhering to therapy. ${ }^{16}$ Suffering with bad experiences associated with ADR may sometimes be intolerable and inflict treatment disruption. ${ }^{39}$ Therefore, ADR could be considered as a barrier for DR-TB patients to achieve treatment adherence. ${ }^{39}$ Some studies had demonstrated that deliberating ADR in DR-TB patients was associated with non-adherence and treatment default or loss to follow-up (Table 2). ${ }^{46,49,50}$ Adherence itself indicates how long a patient follows the healthcare provider's recommendation regarding the received health advice, while loss to follow-up refers to interrupted treatment for at least two consecutive months. Loss to follow-up may indicate nonadherene. Non-adherence in TB therapy may diminish effectiveness of medication and result in higher risk of treatment failure, relapse, and worse drug resistant. ${ }^{51}$

Wang et al found that the incidence of short treatment interruption ( $\leq 14$ days) among 202 MDR-TB patients was $37.6 \%$, and serious interruption ( $>14$ days) was $28.7 \%$. ADR was found to be the most prominent factor of treatment interruption (ORadj: 2.82, 95\% CI: 1.41-5.61) that accounted for $20.3 \%$ of serious interruption, followed by the financial related factor and comorbidity. ${ }^{49}$ Another similar report by Woldeyohannes et al revealed that patients that experienced ADR were six times more likely to become loss to follow-up (AHR $=6.1 ; 95 \% \mathrm{CI}=2.5-$ 14.34). ${ }^{52}$

According to research conducted by Sanchez-Padilla et al (2014), the number of ADR was associated with the loss to follow-up (aRR 1.18, 95\% CI 1.09-1.27). This was reinforced by their qualitative findings based on which all of the patients perceived that dealing with ADR was difficult. Poor tolerability demotivated them from continuing the treatment. The urge of discontinuing was shown to be stronger in the initial period of therapy, and caused losses to follow-up during the intensive phase (69 (71.1\%) of the 97 patient). There were 11 ADR that became the main reason of loss to follow-up. ${ }^{46}$

According to the study by Tupasi et al, among many ADR, high-severity vomit was the only adverse drug reaction that was independently associated with loss to follow-up in multivariate analysis (OR 1.10 (1.01-1.21), $\mathrm{p}=0.03$ ). Additionally, vomit was included in GI disorders, the most common ADR of DR-TB medication. Meanwhile, other side effects, such as dizziness and fatigue exhibited a significant association only in the univariate model. Patients also expressed the fact that their fears toward side effects had been the primary reason for stopping treatments. ${ }^{50}$

Meanwhile, other research studies yielded slightly different results. Research conducted by Iweama et al demonstrated ADR and treatment adherence in both DS-TB and DR-TB. It showed significant bivariate correlation but insignificant multivariate correlation between side effects and treatment adherence. This may be attributed to the fact that because self-reported adherence assessment used in this study may be limited by recall and bias. ${ }^{53}$ Moreover, the proportion of DS-TB patients was higher than DR-TB patients, while DS-TB did not cause severe side effects, like DR-TB did. ${ }^{48}$ Similar results reported by Dela et al 2017, which found a significant association between loss to follow-up with ADR in bivariate analysis $\left(\chi^{2}=20.214\right.$, degrees-of-freedom $=5, p=0.001$ ), as well as between adherence with no occurrence of ADR $\left(\chi^{2}=18.614, \mathrm{df}=1\right.$, $\mathrm{p}=0.000){ }^{54}$

Another study in Philippines demonstrated different results. This study reported that occurrence of uncontrolled adverse events during the first year of treatment was not associated with loss to follow-up $(p=0.35)$ in a univariate analysis. ${ }^{55}$ A retrospective study conducted in Uganda also reported similar results. The study revealed that ADR was not significantly associated with non- 
Table 2 Quantitative Studies of Association Between ADR and Treatment Adherence or Outcome in MDR-TB Patients

\begin{tabular}{|c|c|c|c|c|c|}
\hline $\begin{array}{l}\text { Study } \\
\text { Design }\end{array}$ & Setting & Target & Data Collection & Summary of Result & Reference \\
\hline $\begin{array}{l}\text { Cross } \\
\text { sectional }\end{array}$ & $\begin{array}{l}\text { Guizhou, China, } \\
\text { January-June } \\
2018\end{array}$ & MDR-TB Patients $(n=202)$ & Pill count, interview & $\begin{array}{l}\text { ADR (OR: } 2.82,95 \% \mathrm{Cl}: \mathrm{I} .4 \mathrm{I}- \\
5.6 \mathrm{I}) \text { were the top predictor of } \\
\text { treatment interruption. }\end{array}$ & $\begin{array}{l}\text { Wang et al, } \\
2019^{49}\end{array}$ \\
\hline $\begin{array}{l}\text { Cohort } \\
\text { retrospective }\end{array}$ & $\begin{array}{l}\text { Yerevan, } \\
\text { Armenia, } \\
\text { November 2011 }\end{array}$ & $\begin{array}{l}\text { DR-TB patients who } \\
\text { initiated treatment from } \\
2005 \text { to } 2011(n=381)\end{array}$ & $\begin{array}{l}\text { Ratio of treatment } \\
\text { doses received } \\
\text { under DOT divided } \\
\text { by the number of } \\
\text { doses prescribed. }\end{array}$ & $\begin{array}{l}\text { Number of ADR (aRR I.I8, } 95 \% \\
\mathrm{CI} \text { I.09-I.27) was associated } \\
\text { with loss to follow up from } \\
\text { treatment. }\end{array}$ & $\begin{array}{l}\text { Sanchez-Padilla } \\
\text { et al, } 2014^{46}\end{array}$ \\
\hline $\begin{array}{l}\text { Retrospective } \\
\text { cohort }\end{array}$ & $\begin{array}{l}\text { Oromia region, } \\
\text { Ethiopia, } \\
\text { November 2012- } \\
\text { December } 2017\end{array}$ & DR-TB patients $(n=406)$ & Patient records & $\begin{array}{l}\text { Drug adverse effect (aHR }=6.1 ; \\
95 \% \mathrm{Cl}: 2.5,14.34) \text { were } \\
\text { independent predictors of loss to } \\
\text { follow up. }\end{array}$ & $\begin{array}{l}\text { Woldeyohannes } \\
\text { et al, } 2021^{52}\end{array}$ \\
\hline Case control & $\begin{array}{l}\text { Philippines, } \\
\text { April-July 2014 }\end{array}$ & $\begin{array}{l}\text { DR-TB patients, } \geq 18 \text { years } \\
\text { old, started treatment from } \\
\text { July-December } 2012 \text { (lost to } \\
\text { follow-up cases, } n=91 ; \\
\text { control, } n=182 \text { ) }\end{array}$ & Interview & $\begin{array}{l}\text { Vomit was the only ADR that } \\
\text { associated with loss to follow-up } \\
\text { in multivariate analysis (OR I.I0 } \\
(I .0 I-I .2 I) \text {, P value } 0.03 \text { ) and } \\
\text { reported as the primary reason } \\
\text { for stopping treatment. }\end{array}$ & $\begin{array}{l}\text { Tupasi et al, } \\
2016^{50}\end{array}$ \\
\hline $\begin{array}{l}\text { Cross } \\
\text { sectional }\end{array}$ & $\begin{array}{l}\text { Kano and } \\
\text { Kaduna States, } \\
\text { Nigeria, } \\
\text { January 2015- } \\
\text { June } 2016\end{array}$ & $\begin{array}{l}\text { DS-TB and DR-TB patients, } \\
\text { adult }(n=390)\end{array}$ & $\begin{array}{l}\text { Tuberculosis } \\
\text { Medication } \\
\text { Adherence } \\
\text { Questionnaire } \\
\text { (TBMAQ) }\end{array}$ & $\begin{array}{l}56.7 \% \text { reported that side effects } \\
\text { of anti TB drugs affected their } \\
\text { treatment adherence. } \\
\text { Antituberculosis drugs side } \\
\text { effects were significant variable in } \\
\text { bivariate analysis ( } p<0.00 \mathrm{I}) \text {, but } \\
\text { it was insignificant predictor in } \\
\text { multivariate analysis ( } p=0.191 \text { ). }\end{array}$ & $\begin{array}{l}\text { Iweama et al, } \\
2021^{53}\end{array}$ \\
\hline $\begin{array}{l}\text { Cross } \\
\text { sectional }\end{array}$ & Rajkot, India & $\begin{array}{l}\text { MDR-TB cases during 2010- } \\
2013(n=125)\end{array}$ & Registered data & $\begin{array}{l}\text { Defaulter was associated with } \\
\text { ADR }\left(\chi^{2}=20.214, \mathrm{df}=5, \mathrm{p}=\right. \\
0.00 \mathrm{I}) . \text { Treatment adherence was } \\
\text { associated with no occurrence of } \\
\text { ADR }\left(\chi^{2}=|8.6| 4, \mathrm{df}=\mathrm{I}, \mathrm{P}=\right. \\
0.000) .\end{array}$ & $\begin{array}{l}\text { Dela et al, } \\
2017^{54}\end{array}$ \\
\hline $\begin{array}{l}\text { Retrospective } \\
\text { cohort }\end{array}$ & $\begin{array}{l}\text { Metro Manila, } \\
\text { Philippines }\end{array}$ & $\begin{array}{l}\text { MDR-TB patients treated } \\
\text { from } 1999 \text { to } 2006(n=583)\end{array}$ & Patient records & $\begin{array}{l}\text { Uncontrolled ADR was not } \\
\text { significantly associated with } \\
\text { defaulter }(p=0.35)\end{array}$ & $\begin{array}{l}\text { Gler et al, } \\
2015^{55}\end{array}$ \\
\hline $\begin{array}{l}\text { Retrospective } \\
\text { cohort }\end{array}$ & Uganda & $\begin{array}{l}\text { MDR-TB patients treated } \\
\text { from January 2012-May } \\
2016(n=227)\end{array}$ & Registered data & $\begin{array}{l}\text { ADR was not significantly } \\
\text { associated with non-adherence } \\
(P \text { value }=0.357)\end{array}$ & $\begin{array}{l}\text { Batte et al, } \\
2021^{56}\end{array}$ \\
\hline $\begin{array}{l}\text { Retrospective } \\
\text { cohort }\end{array}$ & $\begin{array}{l}\text { Kerala, Delhi and } \\
\text { West Bengal, } \\
\text { India }\end{array}$ & $\begin{array}{l}\text { MDR-TB in the three States } \\
\text { from January } 2009 \text { to } \\
\text { December } 2011 .\end{array}$ & $\begin{array}{l}\text { Treatment card and } \\
\text { registered data }\end{array}$ & $\begin{array}{l}\text { ADR has no significant } \\
\text { association with unfavorable } \\
\text { outcome ( } P \text { value }=0.09 \text { ) }\end{array}$ & $\begin{array}{l}\text { Nair et al, } \\
2017^{57}\end{array}$ \\
\hline
\end{tabular}

Abbreviations: HRQoL, health-related quality of life; ADR, adverse drug reaction; MCS, mental component summary; PCS, physical component summary; aHR, adjusted hazard ratio; OR, odds ratio; $\mathrm{Cl}$, confidence interval; DR-TB, drug resistant tuberculosis; MDR-TB, multi-drug resistant tuberculosis. 
adherence in MDR-TB patients. ${ }^{56}$ In addition, a study of 788 MDR-TB patients in India suggested no significant association between ADR and unfavorable outcome (failed, died, loss to follow up, transferred out, and switched to Extensively Drug Resistant) both in univariate $(\mathrm{p}=0.07)$ and multivariate $(\mathrm{p}=0.09)$ analysis. ${ }^{57}$ Despite patient's decision to refuse therapy, therapy interruption could sometimes occur owing to the clinician's recommendation regarding severe side effects or the clinical condition. $^{58}$

The occurrence of ADR could be either significantly or insignificantly associated with poor therapy outcomes. ${ }^{58-61}$ Given that non-adherence and treatment interruption was associated with poor outcomes, these states ought to be managed properly. ${ }^{62,63}$

\section{Discussion}

Health care is a humanistic transaction that targets the wellbeing of patients. ${ }^{17}$ Medication, as the part of healthcare, is expected to cure and improve the QoL of patients. Otherwise, in DR-TB therapy, the existing therapeutics regimen was shown to be extremely burdensome for most patients owing to ADR. ${ }^{36,39,45}$ Some studies reported that ADR more likely reduced HR-QoL. ${ }^{20,22}$ ADR is included in the burden of medicine, a term that refers to workloads that are withstood by a person who undergoes therapy and can affect their QoL, especially in a long-term therapy. ${ }^{64-66}$

HR-QoL is more complex than just a health status, it combines some values that a patient expects. ${ }^{17}$ It is about physical, mental, and social well-beings that account for the patients' functionality. ${ }^{27}$ Not only ADR, but other clinical and sociodemographic characteristics are also responsible for the patients' HR-QoL, for example age, smoking, residence, marital status, education level, duration of current treatment, length of sickness before DRTB, HIV comorbid, and number of drugs used. ${ }^{25,27}$ Low QoL predicts poor treatment outcomes owing to its impact to adherence ${ }^{15}$ (Figure 3).

Medication adherence is a complex phenomenon. ${ }^{67}$ In addition to ADR, there were a lot of predisposing factors of DR-TB therapy non-adherence, such as being male, smoking, middle-low education level, being older than 40-45 years old, Extensively Drug Resistant (XDR), or pre-XDR-TB category, and the history of poor TB therapy outcome (loss to follow-up or failed). ${ }^{50,58,68}$ Therefore, ADR may not always be a significant predictor of non-
Sociodemographic \& Clinical Characteristics

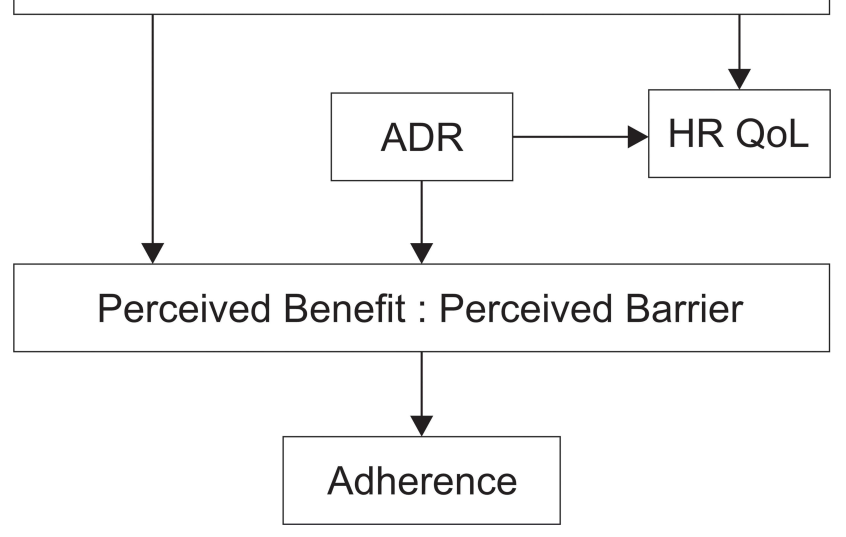

Figure 3 Illustration of burden of ADR and its impact to QoL and adherence. Abbreviations: HRQoL, health-related quality of life; ADR, adverse drug reaction; $\rightarrow$ associated.

adherence. However, ADR is a concern that healthcare workers and care givers should pay attention to.

Based on the health belief model (HBM), perceived barriers and benefits are two direct and prominent aspects that affect adherence. Meanwhile, cues of action, perceived self-efficacy, perceived severity, perceived susceptibility, as well as sociodemographic characteristics and psychological distress were known to be the exogenous variables that indirectly affected adherence. ${ }^{69}$ In this context, the example of perceived barrier is when patients believe that consuming TB drugs costs effort, time, energy, and money owing to ADR. Patients with poor physical well-being may perceive more barriers. The example of perceived benefit is when the patients believe that consuming TB drugs will improve their health states and prevent them from experiencing deteriorating conditions. Patient with good mental well-being will more easily perceive the benefit of therapy. ${ }^{70}$ If perceived benefits outweigh perceived barriers, the patient may adhere to the regimen, and vice versa.

Proper strategies about ADR management have to be planned to maintain QoL and therapy adherence. Proper counseling sessions before and during therapy could build awareness and belief of necessity and convince the patients about the benefit of therapy. Knowledge or educational intervention is one of the primary efforts to strengthen the perceived benefit and reduce the perceived barrier in order to achieve adherence. ${ }^{71,72}$ Healthcare workers have responsibility to deliver information to patients, family, and the caregiver with comprehensive understanding about disease and treatment, including the 
ADR and how to handle ADR. ${ }^{46,69}$ Psychological and educational support could improve both HR-QoL and medication adherence. ${ }^{63,73,74}$

Directly observed treatment (DOT) is very useful to monitor medication usage. DOT from community health workers was known to be more effective to reduce loss to follow-up rate compared with DOT from healthcare workers only from healthcare facilities like hospital. This may be attributed to the fact that healthcare workers in hospital are busy and have only limited time to talk and give support to patients. ${ }^{75}$ In the implementation of DOT, adherence maintenance or improvement is a collaborative approach with a patient-centered perspective. It involves discussions and negotiations to resolve non-adherence. Instead of asking "why," healthcare workers should view non-adherence as a chance to get more information and provide more understanding and motivational support. ${ }^{67}$

Deshmukh et al explained that family, community, and healthcare workers played an important role toward QoL and adherence among DR-TB patients. Hopes and aspiration about future life, concern about their loved ones, and fear of death explained the self-motivation factors for dealing with all barriers. Family and peer attention matter a lot to provide the feeling of security and motivation for patients. ${ }^{58,72}$ Psychological counseling from healthcare professionals was also needed to help patients in relieving anxiety, depression, as well as motivating patients in controlling every barrier. This effort was also effective in improving adherence. $^{70}$

In addition to psychological and cognitive intervention, medical interventions, such as early detection, proper management, and evaluation, were also important. Regular checks and laboratory screenings according to guidelines were needed. ${ }^{76,77}$ Moreover, nutritional support could help patients recover more quickly. ${ }^{78}$

Choi et al recommended that therapeutic drug monitoring (TDM) and pharmacogenomic-based therapy could reduce the potency of ADR as well as increase therapy efficacy. ${ }^{78}$ TDM could help clinicians to find optimal drug concentration which minimize ADR. Combining TDM with microbiological and clinical assessments could help optimize therapy ${ }^{79,80}$ Pharmacogenomic-based individualized therapy allowed clinicians to analyze the risk of ADR that may develop in patients according to their genetic characteristics. There are some polymorphisms that are responsible for the occurrence of ADR in TB therapy. ${ }^{81}$ Yet, this method is barely implemented resource in limited setting, especially in low- and middle-income countries. $^{82}$

However, an effective, safe, and tolerable regimen is currently required. Global need of DR-TB therapy improvement underlies several studies. Since 2016, WHO has recommended a shorter regimen for patients with certain conditions owing to the lower cost and higher adherence potential. ${ }^{83,84}$ Although currently there is no evidence of adherence improvement in shorter regimen, minimizing therapy period will give more confidence of patient to complete the therapy. Shorter regimen also reduces the potency of ADR and diminish therapyrelated cost. ${ }^{56}$ Shorter duration of treatment was also known to be associated with better QoL. ${ }^{22}$ To strengthen the evidence, a multi-centered study is currently being conducted to evaluate HR QoL among patients with shorter regimen. ${ }^{85}$

Several studies has proven safety and efficacy of novel and repurposed drugs for DR-TB. ${ }^{86}$ A randomized control trial showed that Delamanid and Bedaquiline both drugs showed good conversion rate. ${ }^{87}$ The occurrence of QT prolongation has been a concern of using both drugs. ${ }^{88,89}$ Bedaquiline, also showed good clinical outcome in combination with moxifloxacin, pretomanid, and pyrazinamide with shorter regimen. Liver enzyme abnormality was found. ${ }^{90}$ While study in China showed favorable clinical outcome from regimen containing linezolid, fluoroquinolone, clofazimine/bedaquiline, cycloserine, and pyrazinamide. Peripheral neuropathy and arthralgia/myalgia were the most frequent ADR in this regiment. Pyrazinamide and linezolid were two-most ADR inducing drugs. ${ }^{91}$ Based on the existing studies, it can be concluded that delamanid, bedaquiline, clofazimine, pretomanid, fluoroquinolone, and linezolid are novel and repurposed drugs that effective and well tolerated. These agents are promising and may improve QoL and adherence of DR TB patients.

\section{Conclusion and Prospects}

Burden of ADR makes DR-TB therapy to be a miserable period for patients. ADR generally tend to degrade quality of life of patients and potentially influence the adherence. A comprehensive support from family, community, and healthcare provider is required to help patients in coping with the burden of ADR. Nevertheless, the regimen improvement is highly needed. There is still lack of research that conducts analysis of the burden of medicine 
either in general or specifically regarding to ADR. Therefore, this topic ought to be investigated further.

\section{Disclosure}

The authors report no conflicts of interest in this work.

\section{References}

1. World Health Organization. WHO Consolidated Guidelines on Tuberculosis. Module 4: Treatment - Drug-Resistant Tuberculosis Treatment. Online Annexes. World Health Organization; 2020.

2. World Health Organization. Global Tuberculosis Report 2020. Geneva: World Health Organization; 2020.

3. World Health Organization. Safety of Medicines. Vol. 2. Geneva: World Health Organization; 2002.

4. Schnippel K, Berhanu RH, Black A, et al. Severe adverse events during second-line tuberculosis treatment in the context of high HIV Co-infection in South Africa: a retrospective cohort study. BMC Infect Dis. 2016;16(1):1-10. doi:10.1186/s12879-016-1933-0

5. Wu S, Zhang Y, Sun F, et al. Adverse events associated with the treatment of multidrug-resistant tuberculosis: a systematic review and meta-analysis. Am J Ther. 2016;23(2):e521-e530. doi:10.1097/01. mjt.0000433951.09030.5a

6. Schnippel K, Firnhaber C, Berhanu R, Page-Shipp L, Sinanovic E. Adverse drug reactions during drug-resistant $\mathrm{TB}$ treatment in high HIV prevalence settings: a systematic review and meta-analysis. J Antimicrob Chemother. 2017;72(7):1871-1879. doi:10.1093/jac/ $\mathrm{dkx} 107$

7. Xu HB, Jiang RH, Xiao HP. Clofazimine in the treatment of multidrug-resistant tuberculosis. Clin Microbiol Infect. 2012;18 (11):1104-1110. doi:10.1111/j.1469-0691.2011.03716.x

8. Yang TW, Park HO, Jang HN, et al. Side effects associated with the treatment of multidrug-resistant tuberculosis at a tuberculosis referral hospital in South Korea. Medicine. 2017;96(28). doi:10.1097/ MD.0000000000007482

9. Zhang Y, Wu S, Xia Y, et al. Adverse events associated with treatment of multidrug-resistant tuberculosis in China: an ambispective cohort study. Med Sci Monit. 2017;23:2348-2356. doi:10.12659/ MSM. 904682

10. Isaakidis P, Varghese B, Mansoor H, et al. Adverse events among HIV/MDR-TB co-infected patients receiving antiretroviral and second line anti-TB treatment in Mumbai, India. PLoS One. 2012;7(7):e40781. doi:10.1371/journal.pone.0040781

11. Mehta S, Das M, Laxmeshwar C, Jonckheere S, Thi SS, Isaakidis P. Linezolid-associated optic neuropathy in drug-resistant tuberculosis patients in Mumbai, India. PLoS One. 2016;11(9):1-12. doi:10.1371/ journal.pone. 0162138

12. Michalak K, Sobolewska-Włodarczyk A, Włodarczyk M, Sobolewska J, Woźniak P, Sobolewski B. Treatment of the Fluoroquinolone-Associated Disability: the Pathobiochemical Implications. Oxid Med Cell Longev. 2017;2017:1-15. doi:10.1155/ 2017/8023935

13. Borisov S, Danila E, Maryandyshev A, et al. Surveillance of adverse events in the treatment of drug-resistant tuberculosis: first global report. Eur Respir J. 2019;54(6):1901522. doi:10.1183/ 13993003.01522-2019

14. Thomas BE, Shanmugam P, Malaisamy M, et al. Psycho-socioeconomic issues challenging multidrug resistant tuberculosis patients: a systematic review. PLoS One. 2016;11(1):1-15. doi:10.1371/journal.pone. 0147397

15. Mohammed MA, Moles RJ, Chen TF. Medication-related burden and patients' lived experience with medicine: a systematic review and metasynthesis of qualitative studies. BMJ Open. 2016;6(2):e010035. doi:10.1136/bmjopen-2015-010035
16. Eton D, Ramalho de Oliveira D, Egginton J, et al. Building a measurement framework of burden of treatment in complex patients with chronic conditions: a qualitative study. Patient Relat Outcome Meas. 2012:39. doi:10.2147/prom.s34681

17. World Health Organization. WHOQOL User Manual. Geneva: World Health Organization; 1998. doi:10.4091/iken1991.9.1_123

18. Ebrahim S. Clinical and public health perspectives and applications of health-related quality of life measurement. Soc Sci Med. 1995;41 (10):1383-1394. doi:10.1016/0277-9536(95)00116-O

19. Karimi M, Brazier J. Health, Health-Related Quality of Life, and Quality of Life: what is the Difference? Pharmacoeconomics. 2016;34(7):645-649. doi:10.1007/s40273-016-0389-9

20. Valadares RMC, Carvalho W, de Miranda SS. Association of adverse drug reaction to anti-tuberculosis medication with quality of life in patients in a tertiary referral hospital. Rev Soc Bras Med Trop. 2020;53(August):1. doi:10.1590/0037-8682-0207-2019

21. Masumoto S, Yamamoto T, Ohkado A, Yoshimatsu S, Querri AG, Kamiya Y. Factors associated with health-related quality of life among pulmonary tuberculosis patients in Manila, the Philippines. Qual Life Res. 2014;23(5):1523-1533. doi:10.1007/s11136-0130571-x

22. Sineke T, Evans D, Schnippel K, et al. The impact of adverse events on health-related quality of life among patients receiving treatment for drug-resistant tuberculosis in Johannesburg, South Africa. Health Qual Life Outcomes. 2019;17(1). doi:10.1186/s12955-019-1155-4

23. Lange C, Abubakar I, Alffenaar JWC, et al. Management of patients with multidrug-resistant/ extensively drug-resistant tuberculosis in Europe: a TBNET consensus statement. Eur Respir J. 2014;44 (1):23-63. doi:10.1183/09031936.00188313

24. Alene KA, Clements ACA, McBryde ES, et al. Mental health disorders, social stressors, and health-related quality of life in patients with multidrug-resistant tuberculosis: a systematic review and meta-analysis. $J$ Infect. 2018;77(5):357-367. doi:10.1016/j. jinf.2018.07.007

25. Datta S, Gilman RH, Montoya R, et al. Quality of life, tuberculosis and treatment outcome; a case-control and nested cohort study. Eur Respir J. 2020;56(2):1900495. doi:10.1183/13993003.00495-2019

26. Ahmad N, Javaid A, Sulaiman SAS, et al. Effects of multidrug resistant tuberculosis treatment on patients' health related quality of life: results from a follow up study. PLoS One. 2016;11(7):1-16. doi:10.1371/journal.pone. 0159560

27. Jaber AAS, Ibrahim B. Health-related quality of life of patients with multidrug-resistant tuberculosis in Yemen: prospective study. Health Qual Life Outcomes. 2019;17(1):1-14. doi:10.1186/s12955-0191211-0

28. Kuchukhidze G, Kumar AMV, Colombani P, et al. Risk factors associated with loss to follow-up among multidrug-resistant tuberculosis patients in Georgia. Public Heal Action. 2017;7(1).

29. Kassa GM, Teferra AS, Wolde HF, Muluneh AG, Merid MW. Incidence and predictors of lost to follow-up among drug-resistant tuberculosis patients at University of Gondar Comprehensive Specialized Hospital, Northwest Ethiopia: a retrospective follow-up study. BMC Infect Dis. 2019;19(1):1-11. doi:10.1186/s12879-0194447-8

30. Sagwa EL, Ruswa N, Mavhunga F, Rennie T, Leufkens HG, MantelTeeuwisse AK. Adverse events and patients' perceived health-related quality of life at the end of multidrug-resistant tuberculosis treatment in Namibia. Patient Prefer Adherence. 2016;10:2369-2377. doi:10.2147/PPA.S116860

31. Ting NCH, El-Turk N, Chou MSH, Dobler CC. Patient-perceived treatment burden of tuberculosis treatment. PLoS One. 2020;15 (10 October):1-13. doi:10.1371/journal.pone.0241124

32. Sagwa E, Mantel-Teeuwisse AK, Ruswa N, et al. The burden of adverse events during treatment of drug-resistant tuberculosis in Namibia. South Med Rev. 2012;5(1):6-13. 
33. Kastien-Hilka T, Rosenkranz B, Sinanovic E, Bennett B, Schwenkglenks M. Health-related quality of life in South African patients with pulmonary tuberculosis. PLoS One. 2017;12(4):1-20. doi:10.1371/journal.pone. 0174605

34. Nuwagira E, Stadelman A, Baluku JB, et al. Obstructive lung disease and quality of life after cure of multi-drug-resistant tuberculosis in Uganda: a cross-sectional study. Trop Med Health. 2020;48(1). doi:10.1186/s41182-020-00221-y

35. Isaakidis P, Paryani R, Khan S, Mansoor H, Manglani M. Poor Outcomes in a Cohort of HIV-Infected Adolescents Undergoing Treatment for Multidrug-Resistant Tuberculosis in Mumbai, India. PLoS One. 2013;8(7):e68869. doi:10.1371/journal.pone.0068869

36. Gebreweld FH, Kifle MM, Gebremicheal FE, et al. Factors influencing adherence to tuberculosis treatment in Asmara, Eritrea: a qualitative study. J Heal Popul Nutr. 2018;37(1):1-9. doi:10.1186/ s41043-017-0132-y

37. Sturdy A, Goodman A, Joś RJ, et al. Multidrug-resistant tuberculosis (MDR-TB) treatment in the UK: a study of injectable use and toxicity in practice. $J$ Antimicrob Chemother. 2011;66(8):1815-1820. doi:10.1093/jac/dkr221

38. Reuter A, Tisile P, Von Delft D, et al. The devil we know: is the use of injectable agents for the treatment of MDR-TB justified? Int $J$ Tuberc Lung Dis. 2017;21(11):1114-1126. doi:10.5588/ ijtld.17.0468

39. Shringarpure KS, Isaakidis $\mathrm{P}$, Sagili KD, Baxi RK, Das $M$, Daftary A. "When treatment is more challenging than the disease": a qualitative study of MDR-TB patient retention. PLoS One. 2016;11 (3):1-12. doi:10.1371/journal.pone.0150849

40. Horter S, Stringer B, Greig J, et al. Where there is hope: a qualitative study examining patients' adherence to multi-drug resistant tuberculosis treatment in Karakalpakstan, Uzbekistan. BMC Infect Dis. 2016;16(1):1-15. doi:10.1186/s12879-016-1723-8

41. Laxmeshwar C, Stewart AG, Dalal A, et al. Beyond 'cure' and 'treatment success': quality of life of patients with multidrugresistant tuberculosis. Int J Tuberc Lung Dis. 2019;23(1):73-81. doi:10.5588/ijtld.18.0149

42. Deshmukh RD, Dhande DJ, Sachdeva KS, et al. Patient and provider reported reasons for lost to follow up in MDRTB treatment: a qualitative study from a drug resistant TB Centre in India. PLoS One. 2015;10(8):1-11. doi:10.1371/journal.pone.0135802

43. Dos Santos FL, Souza LLL, Bruce ATI, et al. Patients' perceptions regarding multidrug-resistant tuberculosis and barriers to seeking care in a priority city in Brazil during COVID-19 pandemic: a qualitative study. PLoS One. 2021;16(4 April):1-19. doi:10.1371/ journal.pone.0249822

44. Walker IF, Khan AM, Khan AM, et al. Depression among multidrug-resistant tuberculosis patients in Punjab, Pakistan: a large cross-sectional study. Int J Tuberc Lung Dis. 2018;22(7):773-778. doi:10.5588/ijtld.17.0788

45. Huque R, Elsey H, Fieroze F, et al. "death is a better option than being treated like this": a prevalence survey and qualitative study of depression among multi-drug resistant tuberculosis in-patients. $B M C$ Public Health. 2020;20(1):1-13. doi:10.1186/s12889-020-08986-x

46. Sanchez-Padilla E, Marquer C, Kalon S, et al. Reasons for defaulting from drug-resistant tuberculosis treatment in Armenia: a quantitative and qualitative study. Int J Tuberc Lung Dis. 2014;18(2):160-167. doi:10.5588/ijtld.13.0369

47. Brust JCM, Shah NS, Van Der Merwe TL, et al. Adverse events in an integrated home-based treatment program for MDR-TB and HIV in kwazulu-natal, South Africa. J Acquir Immune Defic Syndr. 2013;62 (4):436-440. doi:10.1097/QAI.0b013e31828175ed

48. Carroll MW, Lee M, Cai Y, et al. Frequency of adverse reactions to first-and second line antituberculosis chemotherapy in a Korean cohort. Int J Tuberc Lung Dis. 2019;16(7):961-966. doi:10.5588/ ijtld.11.0574.Frequency
49. Wang Y, Chen H, Mcneil EB, Lu X. Drug Non-Adherence And Reasons Among Multidrug-Resistant Tuberculosis Patients In Guizhou, China: a Cross-Sectional Study. Patient Prefer Adherence. 2019;1641-1653.

50. Tupasi TE, Marie A, Garfin CG, et al. Factors Associated with Loss to Follow-up during Treatment for. Emerg Infect Dis. 2016;22 (3):2012-2014. doi:10.3201/eid2211.160728

51. World Health Organization. Adherence to Long-Term Therapy: Evidence for Action. Geneva; 2003.

52. Woldeyohannes D, Tekalegn Y, Sahiledengle B. Predictors of mortality and loss to follow-up among drug resistant tuberculosis patients in Oromia Hospitals, Ethiopia: a retrospective follow-up study. PLoS One. 2021;71:1-15. doi:10.1371/journal.pone.0250804

53. Iweama CN, Agbaje OS, Christian P, et al. Nonadherence to tuberculosis treatment and associated factors among patients using directly observed treatment short-course in north-west Nigeria: a cross-sectional study. SAGE Open Med. 2021;9:205031212198949. doi: $10.1177 / 2050312121989497$

54. Dela AI, Tank NKD, Singh AP, Piparva KG. Adverse drug reactions and treatment outcome analysis of DOTS-plus therapy of MDR-TB patients at district tuberculosis centre: a four year retrospective study. Lung India. 2017;34(6):522-526. doi:10.4103/0970-2113.217569

55. Gler MT, Podewils LJ, Munez N, Galipot M, Quelapio MID. Tupasi and TE. Impact of patient and program factors on default during treatment of multidrug-resistant tuberculosis. Int J Tuberc Lung Dis. 2015;16(7):955-960. doi:10.5588/ijtld.11.0502.Impact

56. Batte C, Namusobya MS, Kirabo R, Mukisa J, Batte C. Prevalence and factors associated with non-adherence to multi-drug resistant tuberculosis (MDR-TB) treatment at Mulago National Referral Hospital. Kampala Uganda. 2021;21(1):238-247.

57. Nair D, Velayutham B, Kannan T, et al. Predictors of unfavourable treatment outcome in patients with multidrug-resistant tuberculosis in India. Public Heal Action. 2017;7(1):254.

58. Bastard M, Sanchez-padilla E, Hewison C, et al. Effects of Treatment Interruption Patterns on Treatment Success Among Patients With Multidrug-Resistant Tuberculosis in Armenia and Abkhazia. J Infect Dis. 2015;211(10):1607-1615. doi:10.1093/infdis/jiu551

59. Rupani MP, Dave JD, Parmar VB, Singh MP, Parikh KD. Adverse drug reactions and risk factors for discontinuation of multidrug-resistant tuberculosis regimens in Gujarat, western India. Natl Med J India. 2020;33(1):10-14. doi:10.4103/0970-258X.308234

60. Patel SV, Nimavat KB, Alpesh PB, et al. Treatment outcome among cases of multidrug-resistant tuberculosis (MDR TB) in Western India: a prospective study. J Infect Public Health. 2016;9(4):478-484. doi:10.1016/j.jiph.2015.11.011

61. Zhang L, Meng Q, Chen S, et al. Treatment outcomes of multidrugresistant tuberculosis patients in Zhejiang, China, 2009-2013. Clin Microbiol Infect. 2018;24(4):381-388. doi:10.1016/j.cmi.2017.07.008

62. Gelmanova IY, Keshavjee S, Golubchikova VT, et al. Barriers to successful tuberculosis treatment in Tomsk, Russian Federation: non-adherence, default and the acquisition of multidrug resistance. Bull World Health Organ. 2018;85(9):703-711. doi:10.2471/BLT

63. Tola HH, Holakouie-na K, Mansournia MA. Intermittent treatment interruption and its effect on multidrug resistant tuberculosis treatment outcome in. Sci Rep. 2019;9(1):1-10. doi:10.1038/s41598-019-56553-1

64. Tran VT, Barnes C, Montori VM, Falissard B, Ravaud P. Taxonomy of the burden of treatment: a multi-country web-based qualitative study of patients with chronic conditions. BMC Med. 2015;13 (1):1-15. doi:10.1186/s12916-015-0356-x

65. Sav A, King MA, Whitty JA, et al. Burden of treatment for chronic illness: a concept analysis and review of the literature. Heal Expect. 2015;18(3):312-324. doi:10.1111/hex.12046

66. Krska J, Katusiime B, Corlett SA. Patient experiences of the burden of using medicines for long-term conditions and factors affecting burden: a cross-sectional survey. Heal Soc Care Commun. 2018;26 (6):946-959. doi:10.1111/hsc.12624 
67. Gould E, Mitty E. Medication Adherence is a Partnership, Medication Compliance is Not. Geriatr Nurs (Minneap). 2010;31 (4):290-298. doi:10.1016/j.gerinurse.2010.05.004

68. Lalor MK, Greig J, Allamuratova S, et al. Risk Factors Associated with Default from Multi- and Extensively Drug-Resistant Tuberculosis Treatment, Uzbekistan: a Retrospective Cohort Analysis. PLoS One. 2013;8(11):e78364. doi:10.1371/journal. pone.0078364

69. Tola HH, Karimi M, Yekaninejad MS. Effects of sociodemographic characteristics and patients' health beliefs on tuberculosis treatment adherence in Ethiopia: a structural equation modelling approach. Infect Dis Poverty. 2017;6(1):1-10. doi:10.1186/s40249-017-0380-5

70. Tola HH, Shojaeizadeh D, Tol A, et al. Psychological and educational intervention to improve tuberculosis treatment adherence in Ethiopia based on health belief model: a cluster randomized control trial. PLoS One. 2016;11(5):1-15. doi:10.1371/journal.pone.0155147

71. Abiz M, Robabi H, Salar A, Saeedinezhad F. The Effect of Self-Care Education on the Quality of Life in Patients with Pulmonary Tuberculosis. Med Surg Nurs J. 2020;9(2). doi:10.5812/msnj.108877

72. Deshmukh RD, Dhande DJ, Sachdeva KS, Sreenivas AN, Kumar AMV, Parmar M. Social support a key factor for adherence to multidrug-resistant tuberculosis treatment. Indian $J$ Tuberc. 2018;65(1):41-47. doi:10.1016/j.ijtb.2017.05.003

73. Horne R, Chapman SCE, Parham R, Freemantle N, Forbes A, Cooper V. Understanding patients' adherence-related Beliefs about Medicines prescribed for long-term conditions: a meta-analytic review of the Necessity-Concerns Framework. PLoS One. 2013;8 (12):e80633. doi:10.1371/journal.pone.0080633

74. Zhang Y, Zhao X. Effects of the Health Belief Model-Based Intervention on Anxiety, Depression, and Quality of Life in Chronic Obstructive Pulmonary Disease. Neuroimmunomodulation. 2021;28 (3):129-136. doi:10.1159/000512993

75. Toczek A, Cox H, Du Cros P, Cooke G, Ford N. Strategies for reducing treatment default in drug-resistant tuberculosis: systematic review and meta-analysis. Int $J$ Tuberc Lung Dis. 2013;17 (3):299-307. doi:10.5588/ijtld.12.0537

76. Lange C, Aarnoutse RE, Alffenaar JWC, et al. Management of patients with multidrug-resistant tuberculosis. Int $J$ Tuberc Lung Dis. 2019;23(6):645-662. doi:10.5588/ijtld.18.0622

77. Curry International Tuberculosis Centre \& California Departement of Public Health. Drug-Resistant Tuberculosis: A Survival Guide for Clinicians. Third ed. USA: CITC \& the State of California Department of Public Health, Tuberculosis Control Branch (CDPH); 2016.

78. Choi R, Jeong BH, Koh WJ, Lee SY. Recommendations for optimizing tuberculosis treatment: therapeutic drug monitoring, pharmacogenetics, and nutritional status considerations. Ann Lab Med. 2017;37 (2):97-107. doi:10.3343/alm.2017.37.2.97
79. Wilby KJ, Ensom MHH, Marra F. Review of Evidence for Measuring Drug Concentrations of First-Line Antitubercular Agents in Adults. Clin Pharmacokinet. 2014;53(10):873-890. doi:10.1007/s40262-0140170-1

80. Alsultan A, Peloquin CA. Therapeutic drug monitoring in the treatment of tuberculosis: an update. Drugs. 2014;74(8):839-854. doi:10.1007/s40265-014-0222-8

81. Matsumoto T, Ohno M, Azuma J. Future of pharmacogenetics-based therapy for tuberculosis. Pharmacogenomics. 2014;15(5):601-607. doi: $10.2217 /$ pgs. 14.38

82. Olsson S. Overview of pharmacovigilance in resource limited settings: challenges and opportunities. Clin Ther. 2013;35(8):e122e123. doi:10.1016/j.clinthera.2013.07.379

83. Silva DR, Mello FC, Migliori GB. Shortened tuberculosis treatment regimens: what is new? J Bras Pneumol. 2020;46(2):1-8. doi:10.36416/1806-3756/e20200009

84. World Health Organization. What is New in the WHO Consolidated Guidelines on Drug-Resistant Tuberculosis Treatment? Geneva: World Health Organization; 2019. doi:10.4103/ijmr.IJMR 57919

85. Stringer B, Lowton K, James N, Nyang'wa BT. Capturing patient-reported and quality of life outcomes with use of shorter regimens for drug-resistant tuberculosis: mixed-methods substudy protocol, TB PRACTECAL-PRO. BMJ Open. 2021;11(9):1-6. doi:10.1136/bmjopen-2020-043954

86. Grace A, Mittal A, Jain S, et al. Shortened treatment regimens versus the standard regimen for drug-sensitive pulmonary tuberculosis. Cochrane Database Syst Rev. 2019;12.

87. Dooley KE, Rosenkranz SL, Conradie F, et al. QT effects of bedaquiline, delamanid, or both in patients with rifampicin-resistant tuberculosis: a Phase 2, open-label, randomised, controlled trial. Lancet Infect Dis. 2021;21(7):975-983. doi:10.1016/S1473-3099(20)30770-2

88. Pym AS, Diacon AH, Tang SJ, et al. Bedaquiline in the treatment of multidrug- and extensively drug-resistant tuberculosis. Eur Respir J. 2016;47(2):564-574. doi:10.1183/13993003.00724-2015

89. Diacon AH, Pym A, Grobusch MP, et al. Multidrug-Resistant Tuberculosis and Culture Conversion with Bedaquiline. $N$ Engl $J$ Med. 2014;371(8):723-732. doi:10.1056/nejmoa1313865

90. Tweed CD, Dawson R, Burger DA, et al. Bedaquiline, moxifloxacin, pretomanid, and pyrazinamide during the first 8 weeks of treatment of patients with drug-susceptible or drug-resistant pulmonary tuberculosis: a multicentre, open-label, partially randomised, phase $2 \mathrm{~b}$ trial. Lancet Respir Med. 2019;7(12):1048-1058. doi:10.1016/ S2213-2600(19)30366-2

91. Fu L, Weng T, Sun F, et al. Insignificant difference in culture conversion between bedaquiline-containing and bedaquiline-free all-oral short regimens for multidrug-resistant tuberculosis. Int $J$ Infect Dis. 2021;111:138-147. doi:10.1016/j.ijid.2021.08.055
Patient Preference and Adherence

\section{Publish your work in this journal}

Patient Preference and Adherence is an international, peer-reviewed, open access journal that focusing on the growing importance of patient preference and adherence throughout the therapeutic continuum. Patient satisfaction, acceptability, quality of life, compliance, persistence and their role in developing new therapeutic modalities and compounds to optimize clinical outcomes for existing disease states are major areas of interest for the journal. This journal has been accepted for indexing on PubMed Central. The manuscript management system is completely online and includes a very quick and fair peer-review system, which is all easy to use. Visit http:// www.dovepress.com/testimonials.php to read real quotes from published authors. 